\title{
Metaphor of Indian Jewellery - comparing the past and present trends
}

Received: 12.06.2019; Accepted: 27.11.2019

Author for correspondence:

\section{S. Aishwariya}

Department of Textiles and

Clothing, Avinashilingam

University for Women,

Coimbatore, India

Email : aishu55@gmail.com
ABSTRACT : This paper explains the journey of jewellery from the pre-historic times and Mughal era to the present-day faux jewellery. The excavations of the ancient civilisations, have proved that cave man decorated his body using the remains of hunting including the feathers, tooth, paws, skin, tusk and even beaks. Today, various types of materials are used in the making of jewellery which including gold, diamond, emerald, platinum and pearl. Along with the fact that each state and its dance form have a unique form of costume and jewellery which depicts their culture and lifestyle. Jewellery here holds a very prominent place. It is Indians way of life to decorate them from head to toe, but the science and meaning behind them are briefed in this paper.

KEY WORDS: Accessory, Jewellery, Indian jewels, Science behind accessories, Fashion

- HOW TO CITE THIS PAPER : Aishwariya, S. (2019). Metaphor of Indian Jewellery - comparing the past and present trends. Asian J. Home Sci., 14 (2) : 452-457, DOI: 10.15740/HAS/AJHS/14.2/452-457. Copyright@ 2019: Hind Agri-Horticultural Society. 